\title{
The Flexural Strength of Concrete Panels with Crystalline Ceramic Waste Aggregates
}

\author{
Muhtar
}

\begin{abstract}
Increased development has an impact on increasing material requirements and environmental pollution due to waste. Material needs must consider the energy-saving aspects and the thought of useless material to be useful, one of which is a crystalline ceramic waste. The crystalline ceramic waste is very sharp and hard. The utilization of crystalline ceramic waste as a concrete panel material is very important to reduce environmental pollution. The purpose of this research was to utilize crystalline ceramic waste as a concrete panel material and test its flexural capacity. Panel testing was carried out on specimens measuring $30 \mathrm{~mm} \times 400 \mathrm{~mm} \times 800 \mathrm{~mm}$ assuming the panel as a deep beam on simple support. Testing is done by a three-point bending flexural test method. Loading is carried out monotonically until the panel collapses. From the results of the ceramic concrete panel test showed that the flexural strength increased by $31.89 \%$ compared to the flexural strength of normal concrete panels.
\end{abstract}

Keywords: Ceramic concrete panel (CCP), waste aggregate, flexural strength.

\section{INTRODUCTION}

Crystalline ceramic waste is an environmental problem that we must pay attention to because, in addition to being dangerous environmental pollution, it is also increasingly increasing. Therefore it is necessary to have a solution to use it as useful material, including concrete material. Given the large negative impact of crystalline ceramic waste on humans and the environment, the use and utilization of waste as building materials is a must. Utilization and use of renewable energy has been widely studied by researchers to reduce environmental pollution, for example, bamboo as reinforced concrete [1], [2], [3], [4], [17] and the use of crystalline ceramic waste as concrete material [5], [6], [7], [8], [9].

The development of building materials must be energy efficient and think of the use of alternative materials such as crystalline ceramic waste materials. Crystalline ceramic waste is difficult to recycle. The material for making

Revised Manuscript Received on February 05, 2020

* Correspondence Author

Muhtar*, Department of Civil Engineering, Faculty of Engineering, University of Muhammadiyah Jember, Jember, 68121, Indonesia. Email: muhtar@unmuhjember.ac.id

(C) The Authors. Published by Blue Eyes Intelligence Engineering and Sciences Publication (BEIESP). This is an open access article under the CC BY-NC-ND license (http://creativecommons.org/licenses/by-nc-nd/4.0/) crystalline ceramics consists of several basic ingredients such as silica (SiO2), feldspar (Kal3O8), kaolin, clay, and others. All the forming elements are processed starting from mixing the ingredients, processing, printing, until burning with a certain temperature. Fragments of crystalline ceramics are very sharp on the sides, difficult to react with the soil, and can carry out radiation. This is very dangerous for humans and the environment.

The utilization of waste of building materials that are harmful to the environment has been widely done, such as powder from grinding stone waste as a substitute for cement [10] and crystalline ceramic waste powder as a substitute for cement [11], [12], [13], and [14]. Lasseuguette et al. (2019) [11] conclude mortar of results of partial cement replacement with ceramic powder can increase $\mathrm{CSH}$ concentration, high $\mathrm{CSH}$ content shows an increase in mechanical performance such as compressive strength.

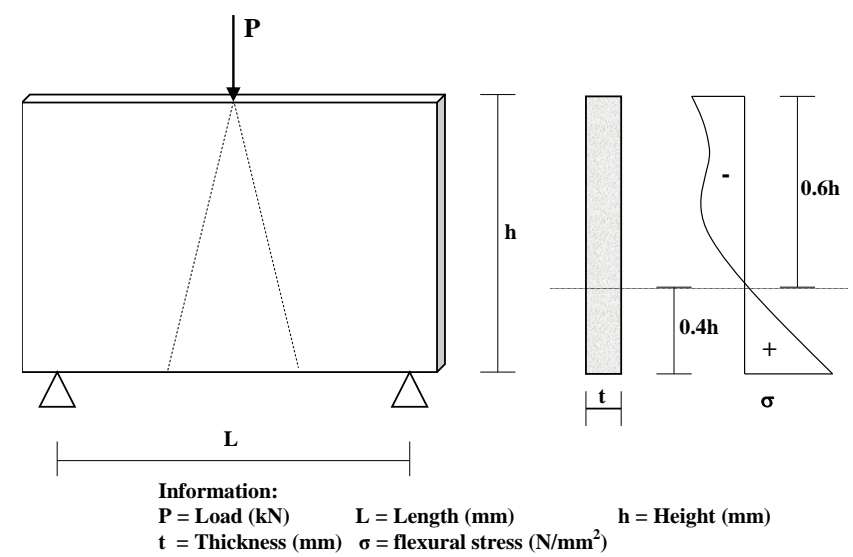

Fig. 1. The crack pattern and flexural stress of deep beam [15]

The concrete compressive strength is linear with a percentage of the amount of ceramic waste aggregate in concrete but has an optimum value both from the availability of material and from its mechanical properties. The optimum proportion of replacing conventional aggregates with ceramic waste aggregates of $30 \%$ is the best proportion [6] The durability of concrete with aggregate crystalline ceramic waste is proven to be more durable [7]. Accurate and control of material properties are very important to improve the mechanical properties of concrete such as concrete compressive strength [8]. The substitution of normal aggregate with CWA aggregate of 55\% obtained the most optimal results [5]. 
Siddique et al. (2019) [9] concluded that for structural concrete the replacement of fine aggregate by $40 \%$ with ceramic waste aggregate provides a characteristic compressive strength and considerable durability. Rashid et al. (2017) [6] the highest compressive strength can be achieved by replacing conventional aggregates with ceramic waste aggregates of $30 \%$. In this study, it was tried to see the potential of ceramic waste to replace a portion of the concrete panel aggregate material. Here it will be observed how flexural strength of the panel when using the aggregate of ceramic waste.

The panel flexural stress distribution is assumed to be a deep beam bending stress distribution based on the ratio of the net span to height ratio $(\mathrm{L} / \mathrm{h})[15]$. Based on the size of ceramic concrete panels for $\mathrm{L} / \mathrm{h}=700 / 400=1.75$ and $\mathrm{h}=$ 350 , the flexural stress of ceramic concrete panels can be included as in Fig. 1. The flexural stress equation is shown in Eq. (1) and Eq. (2). The benefit of this research is to provide hazardous waste utilization solutions without overriding the strength aspects and economic aspects.

$$
\begin{aligned}
& \sigma=\frac{M c}{I}\left(N / \mathrm{mm}^{2}\right) \\
& \sigma=\frac{1.2 P L}{h^{2} t}\left(N / \mathrm{mm}^{2}\right)
\end{aligned}
$$

\section{Material And Methods}

\section{A. Ceramic Waste Aggregate (CWA)}

Crystal ceramic waste is taken from industrial waste that cannot be reprocessed. Crystalline ceramic waste has a thickness that varies between $5 \mathrm{~mm}$ to $15 \mathrm{~mm}$. The types and forms of crystalline ceramic waste used in this study are shown in Fig. 2. Then, crystalline ceramic waste is broken down according to the aggregate size of the plan with a stone grinding machine. The planned size of crystalline ceramic waste aggregate is a maximum of $5 \mathrm{~mm}$ for fine aggregate and for the coarse aggregate of the maximum of $10 \mathrm{~mm}$.

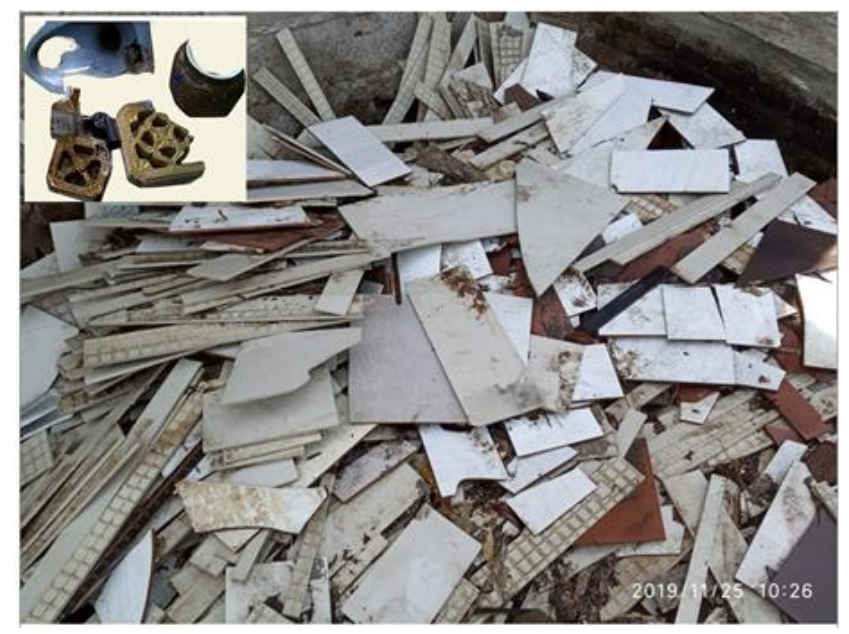

Fig. 2. The types and forms of crystalline ceramic waste

\section{B. Testing Methods}

The research method used is True Experimental Research.
Tests consist of testing of ceramic concrete and testing of ceramic concrete panels (CCP). The size of the concrete panel specimen is $800 \mathrm{~mm}$ x $400 \mathrm{~mm}$ x $30 \mathrm{~mm}$. The ceramic concrete panels (CCP) are made as many as 29 pieces, consisting of 5 variations. The variation of normal partial aggregate replacement with crystalline ceramic waste aggregate is $0 \%$, $25 \%, 50 \%, 75 \%$, and $100 \%$.

The panel bending test is done by a three-point bending flexural test method base on ASTM-D790 [16]. The load is a centralized load spaced $1 \frac{1}{2} \mathrm{~L}$ from the support. The deflection that occurs in the test block is detected using Linear Variable Displacement Transducers (LVDT) at $1 / 2 \mathrm{~L}$ distance from the support. The loading on the panel is provided using a hydraulic jack and $200 \mathrm{kN}$ capacity load-cell connected to the load indicator tool. The load readings on the load indicator are used as deflection reading controllers and hydraulic jacks according to the planned loading stage. After the test object reaches its ultimate load the deflection readings become the controller of the load reading. The arrangement of panels testing and load scheme applied are shown in Fig. 3. The process of making panel test specimens is shown in Fig. 4.

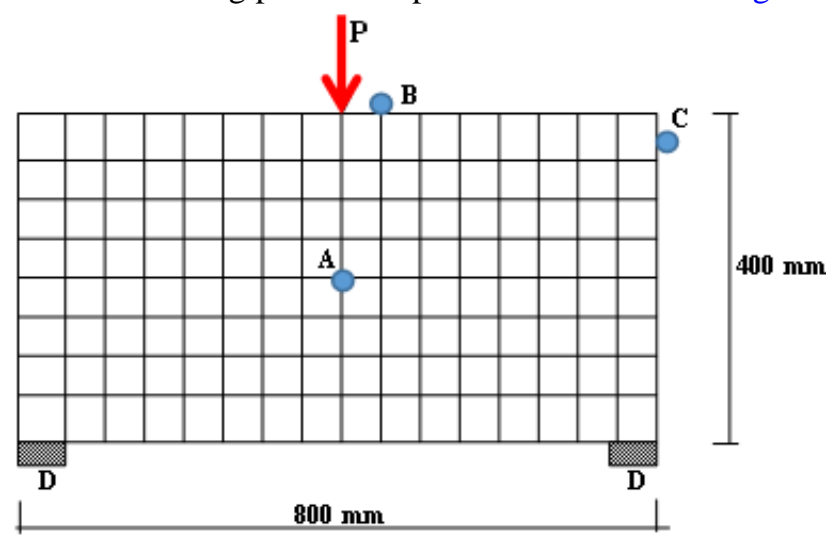

Information:

A, B, C = L VDT (Linear Variable Displacement Transducers)

$\mathrm{D} \quad=$ Support from steel

$\mathrm{P} \quad=$ Centralized load

Fig. 3. Arrangement of testing of panels

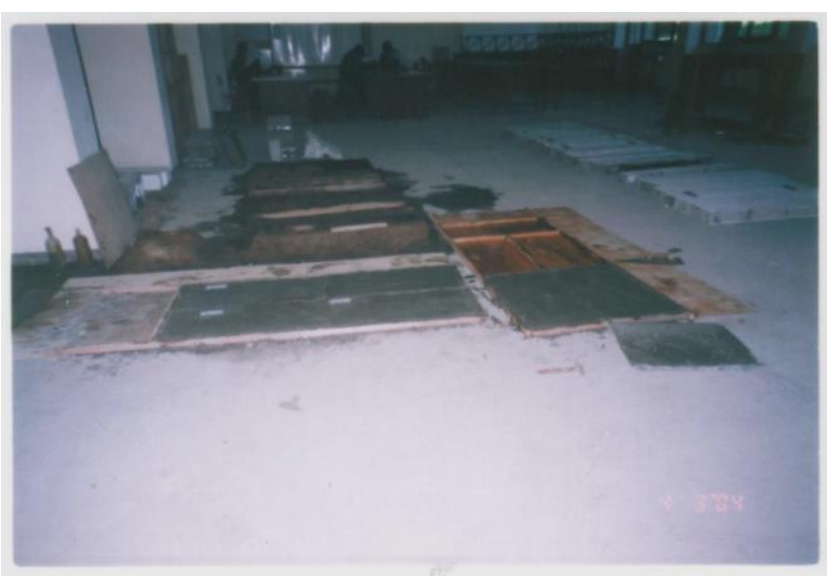

Fig. 4. Manufacture of panel test specimens 


\section{RESULTS AND DISCUSSION}

\section{A. Panel Flexural Strength}

Panel flexural strength testing was carried out on five variations of ceramic concrete panels (CCP) with a thickness of $30 \mathrm{~mm}$, a width of $400 \mathrm{~mm}$, and a length of $800 \mathrm{~mm}$. The number of panel test items is 29 pieces consisting of 10 panels 0\% CWA, 10 panels 75\% CWA, 3 panels 25\% CWA, 3 panels 50\% CWA, and 3 panels 100\% CWA. Panels 0\% CWA and panels 75\% CWA more than other variations, intended to obtain accurate data, because from CWA concrete test data shows that concrete with a variation of $75 \%$ CWA is higher in compressive strength.

From the test results show that the flexural strength of ceramic concrete panels is greater than the flexural strength of normal concrete panels, the more variations in the distribution of CWA aggregates, the greater the flexural strength. The flexural strength of ceramic concrete panels is higher in a row of $9.25 \%, 14.45 \%, 31.89 \%, 23.47 \%$ of the flexural strength of normal concrete panels.

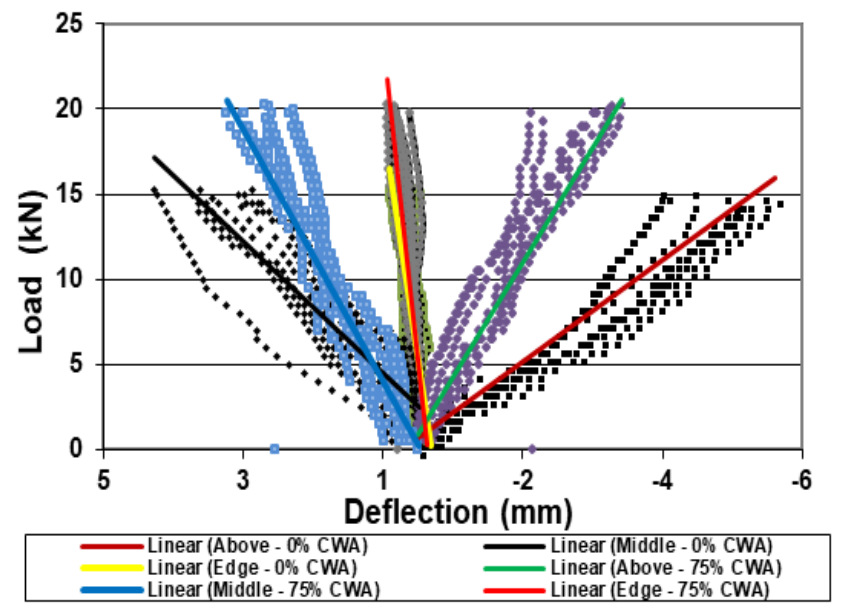

Fig. 5. The relationship of load-displacement of ceramic concrete panels (CCP)

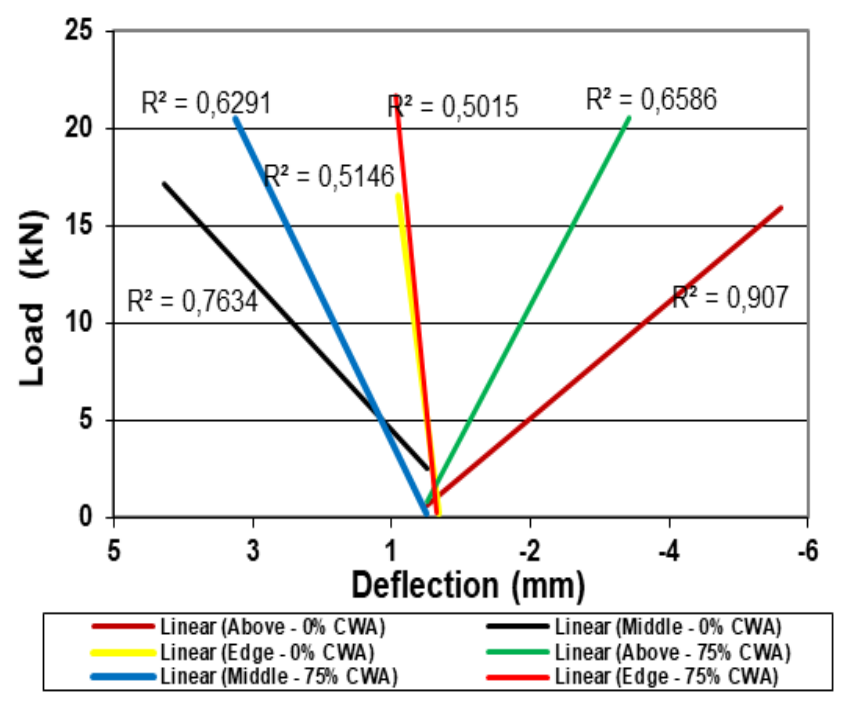

Fig. 6. The regression of load-displacement relations of ceramic concrete panels (CCP)

Fig. 5 and Fig. 6 shows that the displacement of ceramic concrete panels is smaller than the displacement of normal concrete panels, while crack and failure patterns are caused by flexural, however, interval the failure occurs of ceramic concrete panels 75\% CWA longer than normal concrete panels $0 \%$ CWA, this is caused by the CWA aggregate properties that are harder and uniformity of CWA aggregate with normal aggregates, so that the density is better. The spread of the load is better, so the cracks are more diffuse and the ability to accept greater loads. This is evidenced by the crack pattern of the laboratory test results as shown in Fig. 7 and Fig. 8 and the deflection of the results of the finite element method simulation as shown in Fig. 9 and Fig. 10 of the $0 \%$ CWA normal concrete panel and the 75\% CWA ceramic concrete panel. The crack pattern of the $75 \%$ CWA ceramic concrete is more overspread and approaching the crack pattern of Park and Paulay (1975) [15] as shown in Fig. 1 , while the normal concrete panel crack pattern of $0 \%$ CWA shows a straight line down as shown in Fig. 7.

\section{B. The Verification with Finite Element Method (FEM)}

The numerical verification is done to control the suitability of the crack pattern of CCP panels with the stress contour that occurs. The program developed in the FEM analysis was written with the Fortran PowerStation 4.0 program. The analysis of theoretical to calculate the load that causes the initial crack using elastic theory with the section of transformation.

For linear analysis, the material data included are the Poisson ratio $(v)$ and the elastic modulus $(E)$. The constitutive relationship of finite element method (FEM) analysis, the problem-solving method has used the theory of plane-stress.

The quadrilateral elements are used to model plane-stress elements with two-way primary displacement at each point so that the element has eight degrees of freedom. The stress-strain relationship for plane-stress problems has the form of an equation like Eq. (3).

$$
\left\{\begin{array}{c}
\sigma_{x} \\
\sigma_{y} \\
\tau_{x y}
\end{array}\right\}=\frac{E}{\left(1+v^{2}\right)}\left[\begin{array}{ccc}
1 & v & 0 \\
v & 1 & 0 \\
0 & 0 & \frac{1-v}{2}
\end{array}\right]\left\{\begin{array}{c}
\varepsilon_{x} \\
\varepsilon_{y} \\
\gamma_{x y}
\end{array}\right\}
$$

where $E$ is the elasticity modulus and $v$ is Poisson's ratio. And the principal stress in two dimensions is be calculated with Eq. (4).

$$
\sigma_{1,2}=\frac{\sigma_{x}+\sigma_{y}}{2} \pm \sqrt{\left(\frac{\sigma_{x}-\sigma_{y}}{2}\right)^{2}+\tau_{x y}{ }^{2}}=\sigma_{\max }
$$

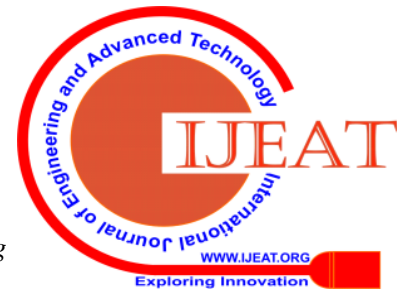


The Flexural Strength of Concrete Panels with Crystalline Ceramic Waste Aggregates

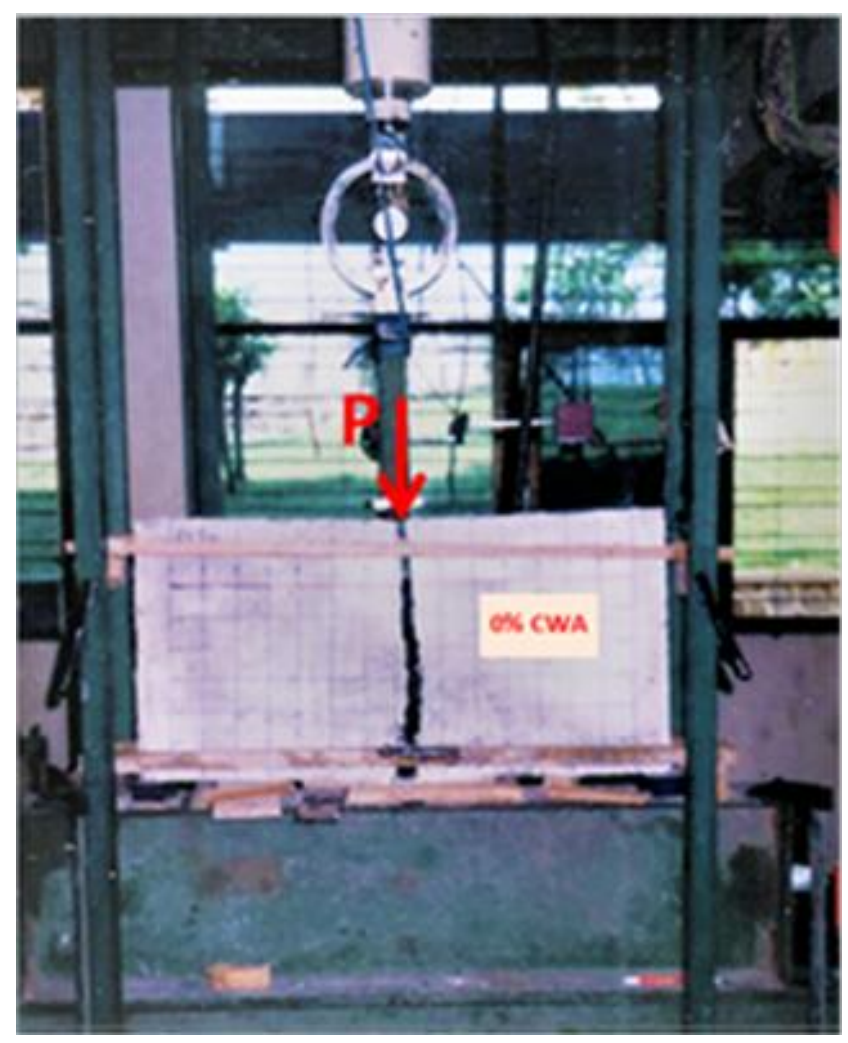

Fig. 7. The crack pattern of normal concrete panels $(0 \%$ CWA)

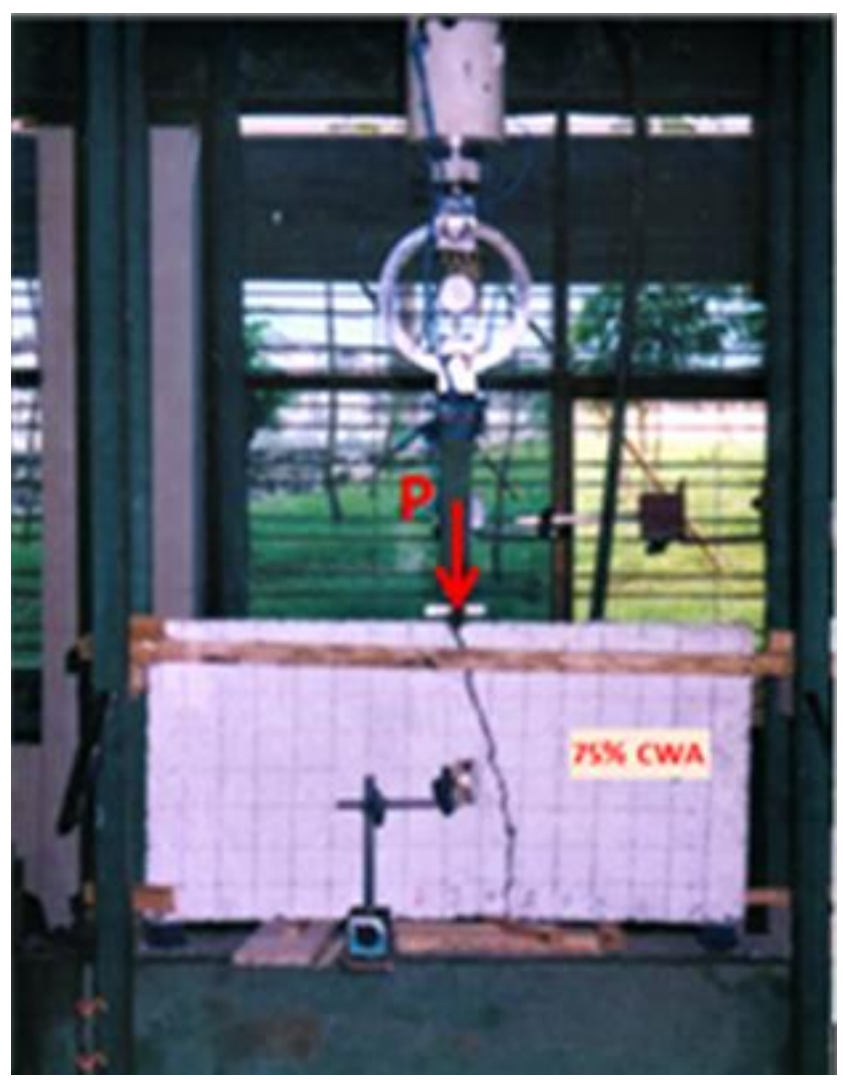

Fig. 8. The crack pattern of ceramic concrete panels $(75 \%$ CWA)

Fig. 11 shows the stress and stress contours at the center point of the panel 0\% CWA and 75\% CWA from the finite element method simulation. As the performance control of the 0\% CWA normal concrete panels and the 75\% CWA ceramic concrete panels, shown the stress at the center point of the panel is as shown in Fig. 11. The stress $\sigma_{11}$ and the stress $\sigma_{22}$ of ceramic concrete panels are larger than normal concrete panels, this proves that ceramic concrete panels have better performance and capacity.

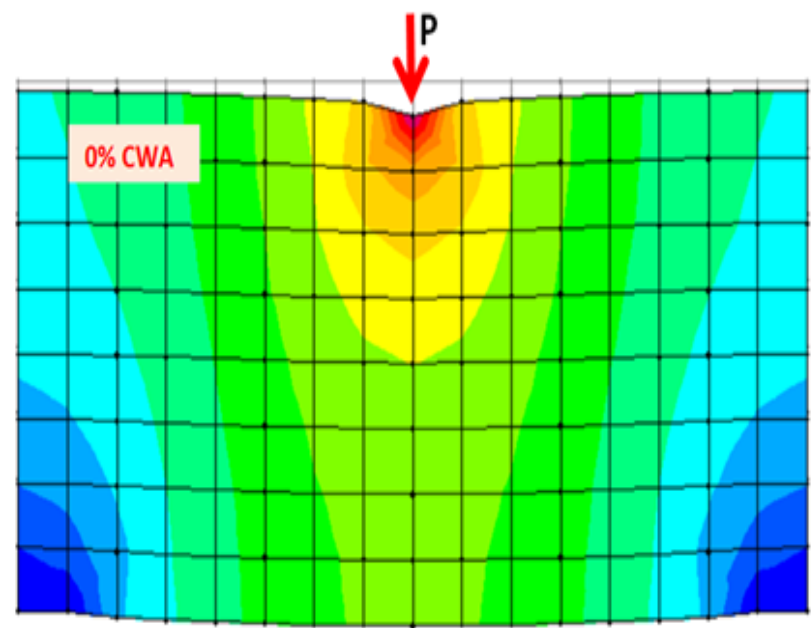

Fig. 9. The deflection contour of normal concrete panels from the FEM simulation (50\% CWA)

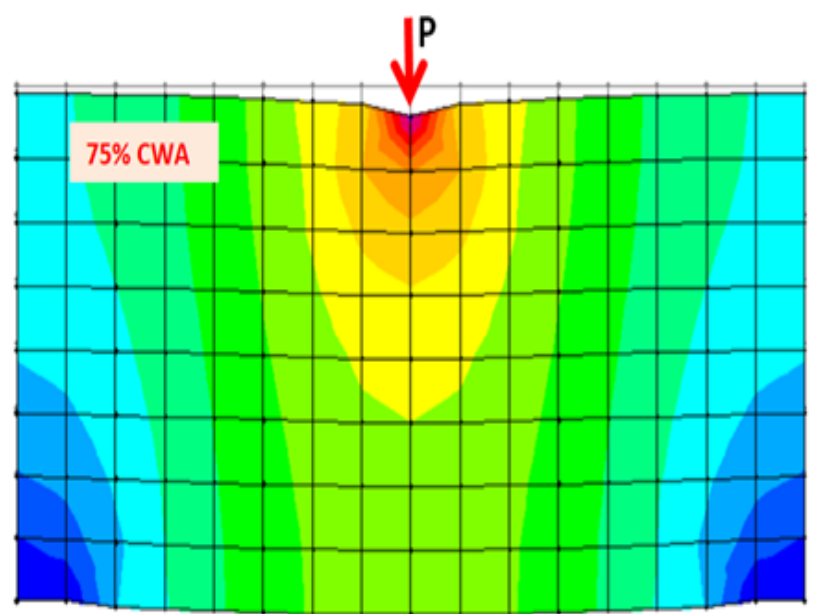

Fig. 10. The deflection contour of ceramic concrete panels from the FEM simulation (75\% CWA)
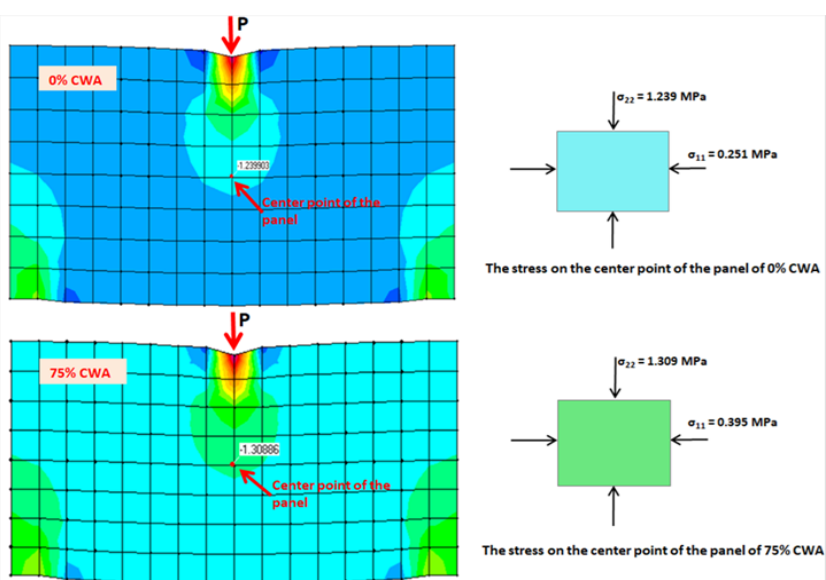

Fig. 11. The stress contour on the center point of the panel of 0\% CWA and $75 \%$ CWA of the FEM simulation results

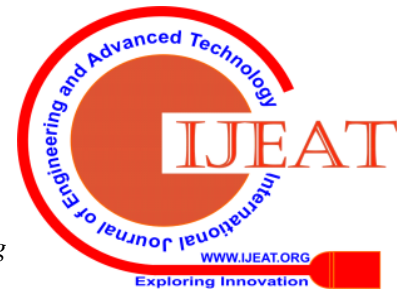




\section{CONCLUSIONS}

From the testing results of the performance of ceramic concrete panels (CCP) obtained several conclusions:

- From the results of flexural testing and the finite element methods (FEM) simulation show that ceramic concrete panels have better performance and greater flexural capacity of up to $31.89 \%$ of the flexural strength of normal concrete panels with $0 \%$ CWA.

- Based on the image of the load and deflection relationship, ceramic concrete panels have a greater stiffness than the normal concrete panel stiffness.

\section{ACKNOWLEDGMENT}

This research and publication were funded fully supported by University of Muhammadiyah Jember through a community service program with a clean environment theme, located at University of Muhammadiyah Jember, Indonesia.
13. M. Samadi, M.W. Hussin, H. Lee, Properties Of Mortar Containing Ceramic Powder Waste As Cement Replacement, Jurnal Teknologi. 77:12 (2015) 93-97.

14. M. Cristiano, The use of ceramic waste aggregates in concrete : a literary review, in Concrete 2014 Progetto e Tecnologia per Il Costruito Tra Xx e Xxi Secolo, 2014. doi:10.13140/2.1.2349.1846.

15. R. Park, T. Paulay, Reinforced Concrete Structures, in John Wiley \& Sons, New York, 1975: pp. 1-769.

16. ASTM-D790, Standard Test Methods for Flexural Properties of Unreinforced and Reinforced Plastics and Electrical Insulating Materials 1, ASTM International, West Conshohocken, PA, 2003.

17. Muhtar, Numerical validation data of tensile stress zones and crack zones in bamboo reinforced concrete beams using the Fortran PowerStation 4.0 program, Data in Brief. (2020) 105332 https://doi.org/10.1016/j.dib.2020.105332.

\section{AUTHORS PROFILE}

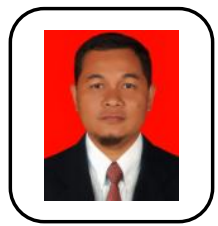

Muhtar, working as a Lecturer in Civil Engineering at the University of Muhammadiyah Jember, Indonesia. Doctor in Structural Engineering from Brawijaya University, Indonesia. Research works in bamboo construction and concrete technology.

\section{REFERENCES}

1. A. Agarwal, B. Nanda, D. Maity, Experimental investigation on chemically treated bamboo reinforced concrete beams and columns, Construction and Building Materials. 71 (2014) 610-617. https://doi.org/10.1016/j.conbuildmat.2014.09.011.

2. Muhtar, S.M. Dewi, Wisnumurti, A. Munawir, The stiffness and cracked pattern of bamboo reinforced concrete beams using a hose clamp, International Journal of Civil Engineering and Technology. 9 (2018) 273-284.

http://www.iaeme.com/MasterAdmin/uploadfolder/IJCIET_09_08_028 /IJCIET_09_08_028.pdf.

3. Muhtar, S.M. Dewi, Wisnumurti, A. Munawir, Enhancing bamboo reinforcement using a hose-clamp to increase bond- stress and slip resistance, Journal of Building Engineering. 26 (2019) 100896. https://doi.org/10.1016/j.jobe.2019.100896.

4. Muhtar, Experimental data from strengthening bamboo reinforcement using adhesives and hose-clamps, Data in Brief. 27 (2019) 104827. https://doi.org/10.1016/j.dib.2019.104827.

5. Muhtar, Effect of Ceramic Waste Aggregate in Concrete to Reduce Environmental Pollution, International Journal of Innovative Technology and Exploring Engineering. 9 (2019) 3112-3117. doi:10.35940/ijitee.B7530.129219.

6. K. Rashid, A. Razzaq, M. Ahmad, T. Rashid, S. Tariq, Experimental and analytical selection of sustainable recycled concrete with ceramic waste aggregate, Construction and Building Materials. 154 (2017) 829-840. doi:10.1016/j.conbuildmat.2017.07.219.

7. C. Medina, M.I. Sánchez De Rojas, C. Thomas, J.A. Polanco, M. Frías, Durability of recycled concrete made with recycled ceramic sanitary ware aggregate. Inter-indicator relationships, Construction and Building Materials. 105 (2016) 480-486. doi:10.1016/j.conbuildmat.2015.12.176

8. D.J. Anderson, S.T. Smith, F.T.K. Au, Mechanical properties of concrete utilising waste ceramic as coarse aggregate, Construction and Building Materials. 117 (2016) 20-28.

doi:10.1016/j.conbuildmat.2016.04.153.

9. S. Siddique, S. Chaudhary, S. Shrivastava, T. Gupta, Sustainable utilisation of ceramic waste in concrete: Exposure to adverse conditions, Journal of Cleaner Production. 210 (2019) 246-255. doi:10.1016/J.JCLEPRO.2018.10.231.

10. H. Alsharie, O. Alayed, The Effect of Replacing Fine Silica with Stone Cuttings ' Powder on the Compressive Strength of Concrete: A Case Study in Jordan, Jordan Journal of Civil Engineering. 13 (2019) 124-135.

11. E. Lasseuguette, S. Burns, D. Simmons, E. Francis, H.K. Chai, V. Koutsos, Y. Huang, Chemical, microstructural and mechanical properties of ceramic waste blended cementitious systems, Journal of Cleaner Production. 211 (2019) 1228-1238. doi:10.1016/j.jclepro.2018.11.240.

12. A.S. El-Dieb, D.M. Kanaan, Ceramic waste powder an alternative cement replacement - Characterization and evaluation, Sustainable Materials and Technologies. 17 (2018). doi:10.1016/j.susmat.2018.e00063.

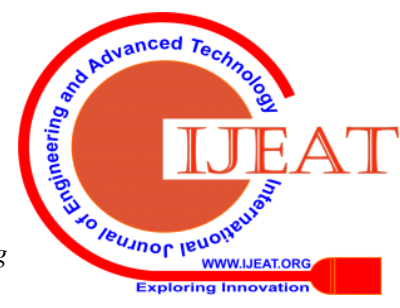

